\title{
Effect of Electronic Secondary Markets on the Supply Chain
}

\author{
ANINDYA GHOSE, RAHUL TELANG, AND \\ RAMAYYA KRISHNAN
}

ANINDYA GHOSE is an Assistant Professor of Information Systems at the Leonard Stern School of Business, New York University. He received his Ph.D. in Information Systems from GSIA, Carnegie Mellon University in 2004. His research interests are in the areas of IT-based price discrimination and customization, estimating demand and efficiency in electronic markets and in the economics of IT security. His recent work has estimated product cannibalization and social welfare in industries transformed by electronic used good markets, the profitability of personalized pricing and quality customization, and the economic incentives for security information sharing. His current work examines pricing and product proliferation in software markets, and dimensions of reputation in e-secondary markets. His research has appeared or is forthcoming in Management Science, Information Systems Research, and Journal of Management Information Systems.

Rahul Telang is an Assistant Professor of Information Systems at John Heinz III School of Public Policy and Management, Carnegie Mellon University. He received his Ph.D. in Information Systems from GSIA, Carnegie Mellon University in 2002. His research interests include consumers' use of new technologies such as search engines and peer-to-peer networks, and empirical and analytical models of software security and vulnerabilities. His current work on e-business examines loyalty on the Internet, competition, and effect of used good markets on retailers and suppliers. His recent papers have studied the impact of patching on software quality, markets for software vulnerabilities, and so on. His research has appeared in Management Science, Journal of Marketing Research, and Journal of Management Information Systems.

RAMAYYA KRISHNAN is the W.W. Cooper and Ruth F. Cooper Professor of Information Systems at the Heinz School of Public Policy and Management at Carnegie Mellon University. His research interests span technology, policy, and business issues related to Internet-enabled systems. He is presently codepartment editor for Information Systems at Management Science.

ABSTRACT: We present a model to investigate the competitive implications of electronic secondary markets that promote concurrent selling of new and used goods on a supply chain. In secondary markets where suppliers cannot directly utilize used goods for practicing intertemporal price discrimination and where transaction costs of resales is negligible, the threat of cannibalization of new goods by used goods become significant. We examine conditions under which it is optimal for suppliers to operate in such markets, explaining why these markets may not always be detrimental for them. Intuitively, secondary markets provide an active outlet for some highvaluation consumers to sell their used goods. The potential for such resales lead to an

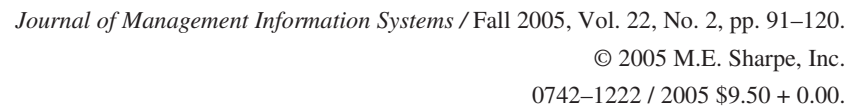


increase in consumers' valuation for a new good, leading them to buy an additional new good. Given sufficient heterogeneity in consumer's affinity across multiple suppliers' products, the "market expansion effect" accruing from consumers' cross-product purchase affinity can mitigate the losses incurred by suppliers from the direct "cannibalization effect." We also highlight the strategic role that used goods commission set by the retailer plays in determining profits for suppliers. We conclude the paper by empirically testing some implications of our model using a unique data set from the online book industry, which has a flourishing secondary market.

KEY WORDS AND PHRASES: electronic markets, information goods, market segmentation, quality degradation, supply chain, used goods.

INFORMATION TECHNOLOGY (IT) REDUCES the search and transaction costs for buyers and sellers to locate and trade products, and can thereby facilitate the creation of technology-mediated electronic exchanges. These Internet-based exchanges allow sellers to easily reach a worldwide market and allow buyers to easily locate items that frequently would be unavailable in traditional physical stores. Consumer-to-consumer exchanges represent one prominent area where the low search and transactions costs in IT-enabled markets have enabled product exchanges that would not have been viable in a comparable bricks-and-mortar environment. The recent establishment of electronic exchanges by some retailers to sell used goods has resulted in a contentious debate about their potential affect on suppliers. For instance, publishers claim that e-tailing giant Amazon.com's high-profile dissemination of used books eats into their often limited royalties and shortens the duration they have to generate new book sales. This has prompted fears that publishers will be forced to raise the prices of new books, in order to extract as high a price as they can, during the onetime sale of a book.

Amazon has argued that its electronic secondary markets actually spur new good sales. Complicating this argument is the fact that Amazon earns about the same from selling a new book as the commission it generates from the sale of a used book on its marketplace [24]. Thus the incentives of the retailers and the publishers are not aligned. In fact, revenue from the commissions generated from secondhand goods (such as books, CDs, DVDs, and packaged software products) are proving to be a moneyspinner for Amazon, and it is expanding its policy of paying commissions to its affiliates to include the sale of used goods.

A salient feature of these information goods is that, once bought, many consumers derive a limited utility from keeping them and are willing to resell them if the transaction costs are negligible. Prior research has shown that IT-enabled electronic markets reduce transaction costs and search costs [3]. For buyers and sellers alike, electronic networks such as the Internet reduce the transaction cost of finding each other without regard to geographical constraints. In addition, buyers incur low search costs when they compare prices and the quality attributes of new and used goods. Since quality 


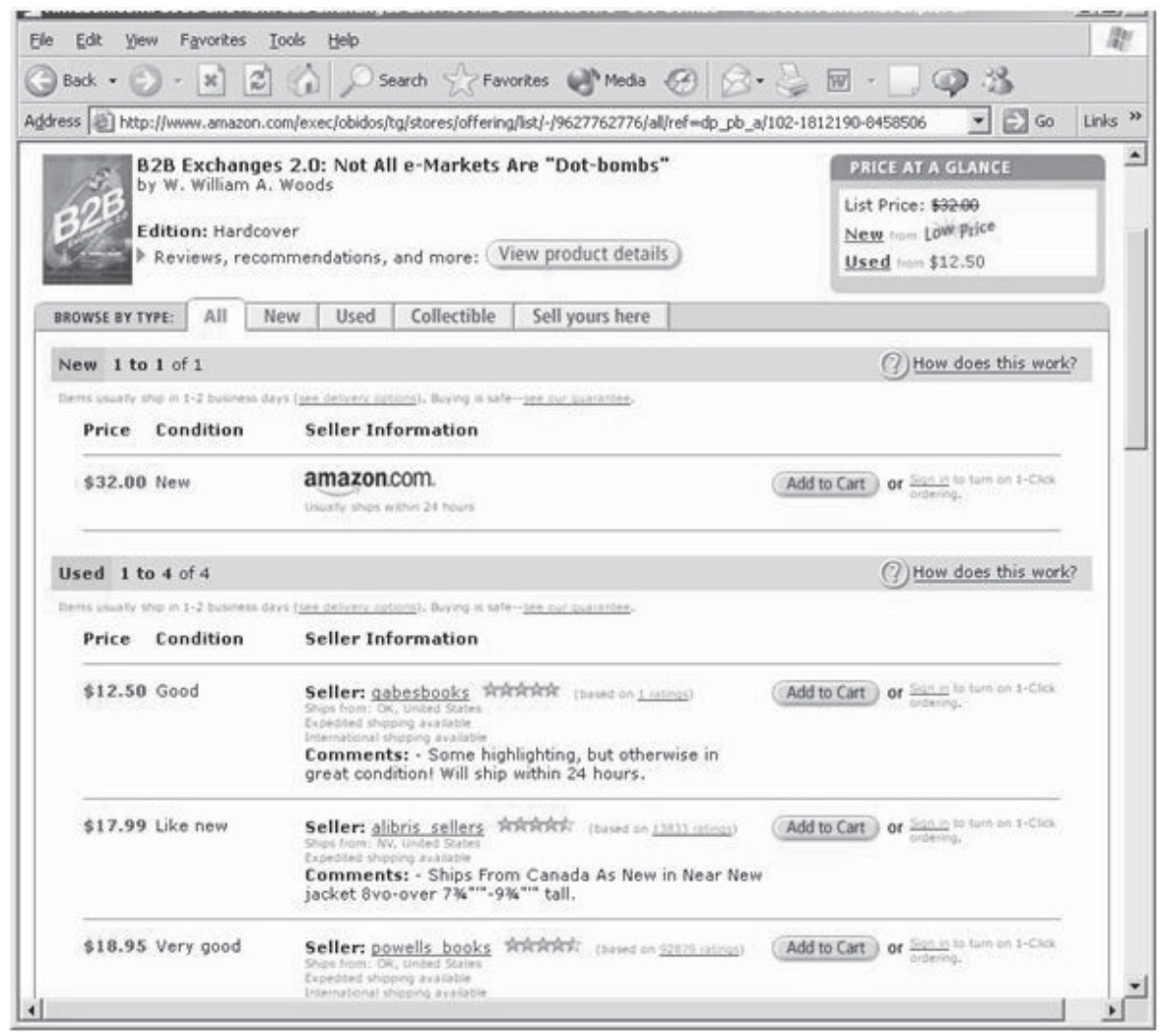

Figure 1. Amazon's Secondary Market with Different Price-Quality Offerings for a Book

depreciation in such goods is usually minimal, consumers find it increasingly profitable or less costly to buy them. Basically, lower prices and tangible quality attributes make them perfectly suitable for trading on such electronic secondary markets.

The nature of durable good markets has long been the subject of active research in economics and marketing. However, the digital economy is changing the nature of interactions in these markets [11]. For example, we observe the concurrent selling of new and used goods with offers of both types of goods being retrieved in response to a user query as shown in Figure 1. In this setting, there is a strong possibility that used goods can cannibalize the sales of new goods.

\section{Literature Review}

THE DIFFICULTY OF MAINTAINING THE MONOPOLY POWER on durable goods is due in part to the problem of time-inconsistency, first pointed out by Coase [8], who conjectured that if a firm were to exploit its residual demand in future periods, then rational consumers would anticipate this behavior and price would fall to the competitive level rapidly. ${ }^{1}$ The interrelationship between the markets for new and used goods was 
first pointed out by Benjamin and Kormendi [4]. They argued that a monopolist can maintain market power, despite an inability to commit to future production, by restricting the used market. ${ }^{2}$ Using the textbook market as an example, Miller [16] suggests that the opening of secondary markets will force publishers to increase new good prices in order to extract the maximum possible profit from the onetime sale of a new good. Liebowitz [15] delineates conditions under which a monopolist will produce goods with a lower durability than under competition. Further research in this area has formalized Coase's conjecture (e.g., Bulow [6], who shows that a monopolist can avoid the commitment problem by leasing as opposed to selling) and pointed out conditions under which it does not hold. For example, Bond and Samuelson [5] show that depreciation reduces the monopolist's incentive to cut price. Kahn [14] shows a similar result by assuming an upward-sloping marginal cost schedule instead of constant marginal costs. Rust [19] solves for consumer behavior and prices for used goods in a durable goods market, with stochastic depreciation. The main argument of these earlier papers [16] is that the secondhand markets need not hurt the manufacturer because they will anticipate the resale value of their product and thereby increase the new good price accordingly.

But a more recent stream of literature [1, 13, 22] has argued that the secondary market also creates a substitution effect that the models above ignore. The substitution effect accrues from the fact that new goods face competition from used goods. Accordingly, some new good consumers will shift to the used good market because of such a substitution effect. Thus the prior literature highlights two countervailing effects of secondary markets. On one hand, used versions of the durable are viewed as substitutes for the newly produced durable good. On the other hand, the price of a durable good is the present discounted value of the benefits stream associated with that good such as a resale. Hence, the optimal extent of any type of interference is conditioned by the relative magnitude of these two effects. An important aspect of the theoretical models in prior literature is that they have explicitly accounted for transaction costs incurred in resales, given that these costs are significant in the physical world. Anderson and Ginsburgh [1] show the monopolist could benefit from imposing a variable transaction fee on buyers of used goods. Waldman [22] and Hendel and Lizzeri [13] show that firms use the lease-only policy of reducing the availability of used goods. Aron and Sundararajan [2] highlight how installed base affects a firm's incentive to have a secondary market. Porter and Sattler [17] introduce a transaction cost for sellers of secondhand goods and show that the volume of trade increases with imperfect substitutability. For a complete survey of the literature on durable goods, see Waldman [23].

Empirical work on used good markets includes a stream of literature looking at adverse selection in used good markets [10]. Genesove [10] finds only modest evidence of adverse selection in dealer auction markets for used cars. Ghose et al. [12] empirically estimate the net loss to publishers due to the cannibalization effect of secondary electronic markets on new book sales. One major contribution of this paper is to propose an alternate rationale as to how secondary markets can mitigate such losses that accrue to suppliers of information goods such as book publishers, record 
labels, and movie studios. Although the sale of used goods is allowed under copyright law, the piracy literature provides many interesting parallels to our work. Piracy may also increase legitimate demand by enabling the producer to credibly commit to not reduce its price in the future [21]. One key difference between pirated and used information goods is the nature of the good itself. Whereas most pirated goods are digital in nature, information goods traded on secondary markets are generally tangible. We also explore the role of used good commissions and discuss associated managerial insights. Specifically, we examine the following: (1) Does the sale of used goods ever benefit suppliers when they cannot accrue any direct profits from secondary market sales? (2) What is the effect of used goods on new good prices and profits? (3) What strategic implications does the used good commission set by the retailer have for suppliers?

\section{Key Results}

PREVIOUS RESEARCH HAS SUBSTANTIALLY ADVANCED our understanding of how durable goods markets function. In contrast to products such as automobiles, we consider information goods, such as books, CDs, DVDs, or software products, where transaction frequency is much higher because transaction and search costs are virtually absent in IT-enabled electronic secondary markets. The success of electronic secondary markets for these types of durable goods, such as those hosted by Amazon or eBay, motivates the need to go beyond existing models. Our model simultaneously accommodates commonly observed phenomena, such as active secondary markets, heterogeneity in consumer preferences, endogenous demand functions, quality depreciation, and the degree of product substitutability between competing goods. Before discussing our model, we highlight three features that distinguish our work from prior research and lead to our main contributions.

First, in our model, we consider two different types of a similar good, each being sold by two different suppliers via one common retailer. There exists an underlying heterogeneity in consumers' purchasing affinity for both goods. Hence the presence of secondary markets not only expands the demand for a specific type of good but also opens up the possibility of some consumers purchasing a second good of another type. The "duopolistic" nature of the market motivates suppliers to compete even more strongly on prices. ${ }^{3}$ Further, the presence of a secondary market allows some consumers to replace their used goods of one type with new goods of the other type. We show that the existence of the secondary market leads to an increase in their valuation for the new good, which in turn can lead to higher supplier profits.

Second, in our model, suppliers do not accrue any direct gains from used good sales and hence they cannot directly use secondhand goods for practicing intertemporal price discrimination. The retailer that acts as an intermediary in our model sets the used good commission and captures all direct secondary market benefits. Consequently, its interests are not aligned with those of the supplier. In such a scenario, the used good commission plays a strategic role by determining the precise change in consumers' implicit disposable income from a resale. From a managerial perspec- 
tive, we show that despite the threat of cannibalization of new goods by used goods, a retailer has a strong incentive to establish a secondary market. While this is always detrimental for suppliers in a monopoly, a duopolistic secondary market leaves them better off, for a wide range of parameters. Further, we show that although increasing the used good commission affects suppliers favorably in a monopoly, it affects them adversely in a competitive scenario.

Third, some consumers derive a positive utility from holding the used good. This feature, along with the duopolistic market structure where a supplier wants to sell its goods in competitor's market, enables suppliers to decrease their prices in the presence of a secondary market. This is in contrast to the conventional perspective that new good prices tend to increase in the presence of a used good market. Further, we point out that irrespective of the nature of the market (monopolistic or duopolistic), an increase in the new good price leads to an increase in the used good price. Using data from Amazon, we provide empirical evidence that corroborates these results.

\section{Model}

\section{Firms}

THE MODEL CONSISTS OF TWO SUPPLIERS, $S_{A}$ and $S_{B}$, selling goods A and B, respectively, through one common retailer, to a unit mass of consumers, each in two different markets. Suppliers are assumed not to have any capacity limits. In our model, one can think of the two suppliers as two publishers or two record labels selling two different books or CDs, respectively. The product $i,(i \in A, B)$ that is sold by each supplier is a durable that provides two periods of service. Thus a new good provides service for two periods, irrespective of the period in which it is bought. A good is new when it is sold in period 1 and the same good is classified as used in period 2. In the first period, only new goods are available. In the second period, the retailer opens a used good market where consumers can buy and sell used goods with minimal transaction costs. The retailer sells both the goods, A and B, supplied by each of the respective suppliers. Whenever the consumer sells a used good (irrespective of whether it is type $\mathrm{A}$ or $\mathrm{B}$ ), the retailer gets a commission $k_{U}$ (where $0<k_{U}<1$ ) per used good sold, whereas the rest $\left(1-k_{U}\right)$ is the gain to the consumer. Similarly it gets $k_{N}$ (where $\left.0<k_{N}<1\right)$ per new good sold, with the rest $\left(1-k_{N}\right)$ going to the supplier. We also assume that the marginal cost of production of each good is zero for the suppliers. This is true for a variety of information goods such as books, CDs, DVDs, videos, journals, shrink-wrapped software, and so on.

\section{Consumers}

Consumers are heterogeneous in their valuations of the good. Let $\theta$ be a consumer's marginal valuation for the quality of a good, where $\theta \in[0,1]$. For any given quality, a consumer with a higher $\theta$ is willing to pay more for the product than one with a lower $\theta$. 
Buying a used good entails a cost of some degree of quality degradation. Let 1 denote the quality of the new good and $q$ denote the quality of the used good in period 2 , where $0<q<1$. Thus $q$ can be interpreted as the degree of intertemporal quality degradation of the new good over two periods. If a consumer purchases a product of quality $q$ at price $p$, his or her utility is $U(\theta)=\theta q-p$. That is, the increase in utility with quality is higher for consumers with higher valuations.

In our model, there are two types of consumers. Type $\mathrm{A}$ consumers have $\theta$ valuation for good A and $\alpha \theta$ valuation for good B where $\alpha \in[0,1]$. Similarly, type B consumers have $\theta$ valuation for good $\mathrm{B}$ and $\alpha \theta$ valuation for good $\mathrm{A}$. The parameter $\alpha$ is the degree of consumers' affinity for the other product such that the higher the value of $\alpha$, the more intense is the competition between the two suppliers for inducing the consumers to buy their goods. When $\alpha=0$, consumers strictly prefer the specific good $i \in(A, B)$ according to their respective types. However, $\alpha>0$ implies consumers have an incentive to buy both goods. In this paper, we refer to $\alpha$ as the cross-product purchase affinity parameter.

Having bought a new good in period 1, consumers can either hold onto the good or sell it as a used good in the market in the second period. Intuitively, we would expect that for the same $\theta$, a consumer holding the good will derive less utility than a used good buyer. Therefore, we assume that while the buyer of a used good derives a utility of $\theta q$, the holder of the used good derives a utility of $\theta h$, where $h<q$. To motivate this discussion, consider a good such as a DVD or a fiction novel. Once a consumer has seen the movie or read the novel, his or her utility from the product content will decline. As such, he or she will derive a lower utility from holding the good. Conversely, a buyer of the same used DVD or novel can derive a much higher utility from the content of the good. Hence, depending on the prices of both goods and consumers' relative preference for each good $(\alpha)$, they may choose to buy one or both the goods. The game is modeled as a multistage process across two periods. We consider a subgame-perfect equilibrium of this game using backward induction.

\section{No Electronic Secondary Market}

WE BEGIN WITH THE BENCHMARK CASE when there is no market for used goods. This allows us to do comparative statics when an active used good market exists. We consider two separate cases:

1. Case 1: "Monopoly Without Used Goods Case." In this case, consumers purchase, at most, one good from either supplier, according to their type $i, i \in$ $(A, B)$.

2. Case 2: "Duopoly Without Used Goods Case." In this case, some consumers are interested in purchasing both goods, one from each supplier $i, i \in(A, B)$.

Throughout the rest of the paper, we refer to these scenarios as the "no used good case" for both monopolistic and duopolistic markets. We solve for the equilibrium price in both cases. We will then perform a similar analysis in the presence of a used 
good market and do some comparative statics. These comparisons enable us to highlight the effect of a secondary market on suppliers and the retailer.

\section{Case 1: Monopoly Without Used Goods}

Since there is no secondary market, consumers can only do the following: buy the new good $(N)$ in the first period and hold it $(H)$ in the second period. In the second period, for a consumer of type $\theta$, the utility derived from holding it is simply $\theta h$. We denote the price of a new good in this scenario as $P^{N}{ }_{m n}$, where the superscript $N$ denotes that it is the price of a new good and the subscript $m n$ denotes that it is the "monopoly without used goods case." A consumer of type $\theta$ in each market will buy a good as long as $\theta(1+h)-P^{N}{ }_{m n} \geq 0 \Leftrightarrow \theta^{\prime}=P^{N}{ }_{m n} / 1+h$, where $\theta^{\prime}$ is the consumer indifferent to buying a good and not buying at all. Here, $P^{N}{ }_{m n}$ can be interpreted as the monopoly price that $S_{A}\left(S_{B}\right)$ offers to all consumers. ${ }^{4}$ At this price, the demand for a new good (both A and B) is $D_{n}\left(P^{N}{ }_{m n}, h\right)=1-P^{N}{ }_{m n} / 1+h$. The profit for each supplier is $\Pi^{N}{ }_{m n}(S)=\left(1-\left(P^{N}{ }_{m n} / 1+h\right)\right)\left(1-k_{N}\right) P^{N}{ }_{m n}$ from which the optimal price $P^{N^{*}}{ }_{m n}=((1+$ $h) / 2$ ) is obtained. Each supplier makes a profit of

$$
\Pi_{m}^{N}(S)=\frac{(1+h)}{4}\left(1-k_{N}\right),
$$

whereas the total profit of the retailer from both the markets is

$$
\Pi_{m}^{N}(R)=\frac{(1+h) k_{N}}{2}
$$

Note that the implicit assumption here is that consumers have a disposable income $I$ equal to at least the price of one new good-that is $\left((1+h) k_{N}\right) / 4$ - to be able to purchase the good.

Lemma 1 (Monopoly Prices Without Used Goods): For all $\alpha \in(0,0.61)$, both suppliers offer the monopoly price $\left(\mathrm{P}_{\mathrm{mn}}^{\mathrm{N}}, \mathrm{P}_{\mathrm{mn}}^{\mathrm{N}}\right)$ and consumers buy, at most, one good of their type.

For $\alpha \geq 0.61$, each supplier poaches into its rival's market and a stiff price competition ensues. ${ }^{5}$ Hence, to focus on the implications of a secondary market on suppliers and the retailer, we will consider the case of $\alpha \leq 0.61$ in the subsequent discussion for the monopolistic market. It is also worth noting that if consumers did not derive any utility from holding the good, then the optimal price $P^{N}{ }_{m n}$ suppliers could have charged would have been equal to $1 / 2$. The increased utility from holding the good is what drives suppliers to charge the extra price $h / 2$.

In the absence of a secondary market, the profit-maximizing prices for the retailer and the suppliers are the same. However, when there is a secondary market, the strategies for the retailer and suppliers change, because although the retailer still gets a commission for each used good sold, the suppliers do not. ${ }^{6}$ It is this differential incen- 
tive for used good sales between suppliers and retailers and the consequent implications for equilibrium profits that we aim to explore in this paper.

\section{Case 2: Duopoly Without Used Goods}

Now, we consider the case when some consumers can purchase both goods. That is, some consumers of type A are willing to also buy good B and vice versa. In the previous equilibrium, we showed that both suppliers simultaneously offer monopoly prices when consumers are buying one good according to their type. Clearly, the suppliers' pricing strategy will change when each supplier can sell its good in the other's market as well.

Let the subscript $d n$ denote the duopoly market with no used goods. Suppose $S_{A}$ offers price $P^{N}{ }_{d n}$ such that in a type B market, some consumers find it incentive compatible to buy both good A and B at lower prices, as long as it satisfies their individual-rationality constraint. Hence, the type B market gets split into two segments, such that the higher willingness to pay consumers buy both good B and good A, whereas the remaining buyers buy only good $\mathrm{B}$. It follows that all type B consumers between $\theta_{1}$ and 1 also buy from $S_{A}$. By symmetry, supplier $S_{B}$ will do the same in a type A market by setting a price $P^{N}{ }_{d n}$. We formally show that there exists a pure strategy equilibrium in prices.

Lemma 2 (Duopoly Prices Without Used Goods): When some consumers can buy two goods, the optimal price and supplier profits are given by $\mathrm{P}^{\mathrm{N} *}{ }_{\mathrm{dn}}=(\alpha(1+\mathrm{h})) /$ $(1+\alpha)$ and $\Pi_{\mathrm{d}}^{\mathrm{N}}(\mathrm{S})=\left(1-\mathrm{k}_{\mathrm{N}}\right)(\alpha(1+\mathrm{h}) /(1+\alpha))$, respectively.

It is critical to note that in order for consumers to buy both goods, they should have a disposable income $I$ equal to at least twice the price of a new good-that is, $2 \alpha(1+$ $h) /(1+\alpha)$. If this is not so, then they can buy only one good, which will be sold at the monopoly price as shown in the last section. Next, we show that when a secondary market is established, the disposable income required to buy both goods reduces considerably because consumers are able to trade their used good for some extra income. This increases their valuation for a new good and, in turn, positively affects the supplier's and retailer's profitability. ${ }^{7}$

\section{Retailer Establishes an Electronic Secondary Market}

IN THIS SCENARIO, CONSUMERS ARE AWARE that in period 1, only new goods are available, whereas in period 2, both new and used goods are available. Consumers who purchase the new good in period 1 always have the option of selling their used good in a secondary market in period 2 . Thus at the beginning of each period, when consumers evaluate their needs over the two-period horizon, they can follow one of five independent strategies laid out below. Let $P^{U}{ }_{m n}$ and $P^{U}{ }_{m s}$ denote the new good and used good prices, respectively, where the superscript $U$ indicates the presence of a 
secondary market. The subscripts $m s$ and $m n$ denote a monopolist with and without used good cases, respectively.

Let $N^{i}, H, S, U$, and $I$ denote a single-period action, corresponding to buying a new good of type $i$, holding onto a used good, selling a used good, buying a used good, and remaining inactive by not buying any good. We state a general formulation of underlying utility and then endogenously derive the consumer demand functions. ${ }^{8}$ Doing so enables us to get a better understanding of consumer strategies and the trade-offs involved in choosing among the differentiated products. Similar to the previous section, we will again focus on two separate cases.

1. Case 3: "Monopoly with Used Goods Case." Consumers are interested in purchasing at most one good.

2. Case 4: "Duopoly with Used Goods Case." Some consumers purchase both goods.

\section{Case 3: Monopoly with Used Goods}

We next discuss a supplier's problem of determining the optimal new good price when the retailer establishes a used good market. We assume the used market is competitive and neither the supplier nor the retailer has any direct control in setting the used good price. Hence, a used good sale does not provide any explicit benefit to the suppliers. When consumers buy, at most, one good, they buy their preferred good according to the market type to which they belong. That is, consumers of type A(B) buy good A(B). Therefore, the corresponding utilities derived from various action strategies are as follows:

1. $(N H)$ : Buy new good in period 1 and hold onto the used good in period 2: $\theta(1+h)-P^{U}{ }_{m n}$.

2. (NS): Buy new good in period 1 and sell used good in period 2: $\theta-P_{m n}^{U}+(1-$ $\left.k_{U}\right) P_{m s^{U}} \cdot$

3. (IU): Remain inactive in period 1 and buy used good in period 2: $\theta q-P_{m s}^{U}$.

4. Remain inactive in both periods: 0 .

Figure 2 describes the segmentation of the market based on consumer action strategies. Recall that in this case a consumer is interested in buying at most one good. Note that the condition $q\left(1-k_{U}\right)>h$ needs to hold for such a market segmentation. Intuitively, this means that some consumers derive a higher utility from selling the used good than holding onto it. Further, the holding utility also needs to be such that any consumer finds it incentive compatible to hold on to a used good, instead of selling it. ${ }^{9}$

Using the individual-rationality and the incentive-compatibility constraints, we derive the three indifferent points that define the consumer market segments. The market cutoffs are as follows:

$$
\theta_{1}=\frac{\left(1-k_{U}\right) P_{m s}^{U}}{h} \theta_{2}=\frac{P_{m n}^{U}-\left(2-k_{U}\right) P_{m s}^{U}}{1-q} \theta_{3}=\frac{P_{m s}^{U}}{q}
$$




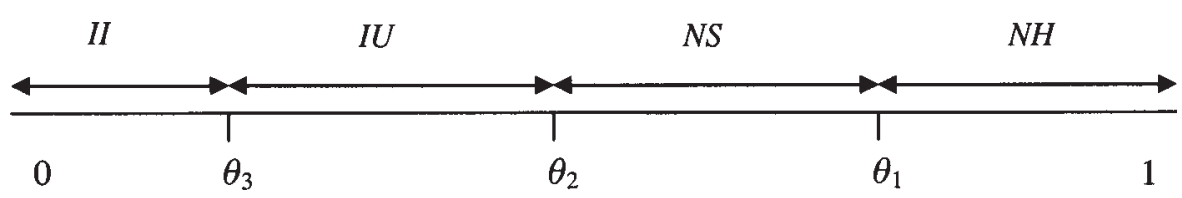

Figure 2. Consumer Consumption Classes in a Monopoly with Used Goods

Note that the number of consumers in any group is given by the length of that segment. It is important to recognize that, in our model, based on suppliers' pricing strategies, the number of consumers in these groups will emerge endogenously. Since the used good market is competitive, the price of used goods, $p_{s}$, will also be endogenously determined. This ensures that the market-clearing conditions equalize supply and demand of used goods. All consumers from $\theta_{1}$ to $\theta_{2}$ are suppliers of used goods. All consumers from $\theta_{2}, \theta_{3}$ create the demand for used goods. By equating demand with supply, we get the market clearing used good price, $P^{U}{ }_{m s}$. The optimal new good price, $P^{U^{*}}{ }_{m n}$, is derived from the supplier's profit equation, after substituting for $P_{m s}^{U}$. The supplier's profit equation is given by $\Pi_{m}^{U}(S)=\left(1-\theta_{2}\right)\left(1-k_{N}\right) P^{U}{ }_{m n}$. From this equation, the optimal $P^{U^{*}}$ sn set by the supplier and the market clearing used good price $P^{U^{*}}{ }_{m s}$ can be derived as

$$
\begin{gathered}
P_{m n}^{U^{*}}=\frac{\left(1-k_{U}\right)(1-q) q+h\left(1+\left(3-2 k_{U}\right) q\right)}{2\left(h+q-k_{U} q\right)} \\
P_{m s}^{U^{*}}=\frac{h q}{h+q-k_{U} q},
\end{gathered}
$$

which gives the supplier's profit as

$$
\Pi_{m}^{U}(S)=\left(1-k_{N}\right)\left(\frac{\left(1-k_{U}\right)(1-q) q+h\left(1+\left(3-2 k_{U}\right) q\right)}{4\left(h+q-k_{U} q\right)}\right)=\left(\frac{1-k_{N}}{2}\right) P_{m n}^{U^{*}}
$$

and the retailer's profits as

$$
\Pi_{m}^{U}(R)=\frac{k_{N} \Pi_{m}^{U}(S)}{1-k_{N}}+\frac{h k_{N} q\left(\left(1-k_{U}\right) q-h\right)}{2\left(h+q\left(1-k_{U}\right)\right)^{2}}
$$

Proposition 1 (New Good Price and Supply-Chain Profits): (i) The optimal new good price, $\mathrm{P}_{\mathrm{m}}^{\mathrm{u}}$, in the monopolistic "used good" market is lower than the new good price in a monopolistic "no used good" market, $\mathrm{P}_{\mathrm{m} \text {. }}^{\mathrm{N}}$ (ii) While the suppliers' profits decrease with the establishment of a secondary market, there exists a $\mathrm{k}_{\mathrm{U}}$ such that for all $\left.\mathrm{k}_{\mathrm{U}} \geq \mathrm{k}_{\mathrm{N}}\left(\mathrm{q}^{2}-\mathrm{h}^{2}\right)\right) / \mathrm{q}\left(\left(2-\mathrm{k}_{\mathrm{N}}\right) \mathrm{h}+\mathrm{k}_{\mathrm{N}} \mathrm{q}\right)$, the retailer's profits increases in a secondary market. 
The presence of an active used goods market creates competition for new goods because the option of buying used goods is now incentive-compatible for some consumers who would have bought new goods before. This enhanced competition forces suppliers to decrease new good prices in order to remain competitive with used goods. Recall that the supplier cannot derive any benefit from the sale of used goods, since all the used goods commission is forfeited to the retailer. In contrast to conventional wisdom, we find that the price of a new good decreases from the case when there is no used good market to when there is an active used good market. This is surprising, but the intuition accrues from the fact that the existence of the $\mathrm{NH}$ segment discourages suppliers from raising prices..$^{10}$ Thus we point out that as long as some consumers derive a positive utility from holding a used good, suppliers will not raise the new good price, despite the establishment of a secondary market by an intermediating retailer.

On the other hand, if we compare retailer profits in both cases, we observe that, in general, retailer profits increase with the establishment of a secondary market. The loss from lower profit margins per customer in $N H$ and $N S$ segments is more than offset by the gain from additional sales in the $I U$ segment. This result highlights why retailers of durable goods who split the gains from used good sales with consumers only (not with suppliers) have a strong incentive to open a secondary market.

Proposition 2 (Effect of Used Good Commission on Prices): The optimal new good and used good price increases monotonically with an increase in used good commission fees, $\mathrm{k}_{\mathrm{U}}$.

The analysis above has interesting managerial and public policy implications. First, even though secondary markets leave suppliers worse off, in general, the retailer is better off by prudently setting the used good commission after observing the supplier's new good commission. More importantly, consumers are always better off. Therefore, from a policy perspective, even though secondary markets are detrimental for suppliers, they do enhance consumer welfare. Second, the analysis allows us to observe the effect of various parameters on firms' optimal strategies. For example, retailers such as Amazon will be interested in setting an optimal commission $k_{U}$. When the used good commission $k_{U}$ increases, the used good market shrinks in size while the new good market expands. This leads to higher supplier profits. Although this tends to lower profits for the retailer from used good sales, it is compensated by the increased profits from the new good market. But importantly, unlike suppliers, the retailer benefits twice from the $N S$ segment: it earns the commission twice in the form of $k_{N}$ and $k_{U}$. Therefore, with a higher used good commission, eventually, the used good market shrinks enough to start decreasing the retailer's net profits. Clearly, then, beyond a critical value of $k_{U}$, the retailer's incentive to increase $k_{U}$ is at odds with that of the suppliers, who always prefer a shallow used good market. Formally, the optimal $k_{U}$ for the retailer is shown below.

Proposition 3 (Optimal Used Good Commission): (i) The optimal retailer profitmaximizing used good commission, $\mathrm{k}_{\mathrm{U}}$, is given by $\mathrm{k}_{\mathrm{U}}{ }^{*}=\left(\left(\mathrm{q}^{2}-\mathrm{h}^{2}\right)\left(1+\mathrm{k}_{\mathrm{N}}\right)\right) /$ 
$\left(\mathrm{q}\left(\mathrm{q}+3 \mathrm{~h}+\mathrm{k}_{\mathrm{N}}(\mathrm{q}-\mathrm{h})\right)\right)$. (ii) Further, as the supplier's new good commission $\mathrm{k}_{\mathrm{N}}$ increases, the retailer's optimal used good commission $\mathrm{k}_{\mathrm{U}}{ }^{*}$ also increases.

Intuitively, a higher $k_{N}$ implies the retailer generates more profit from the new good market. Hence, its best response is to minimize the size of the used good market by increasing $k_{U}$, thereby making it less profitable for consumers to sell the used good. Basically, by strategically increasing $k_{U}{ }^{*}$, the retailer can alter the size of the $N H$ segment vis-à-vis the NS segment and thus make higher profits. ${ }^{11}$ This analysis highlights the effect of a secondary market on a monopolistic supplier, and a retailer's profits, as well as on consumer welfare. One key contribution is to analyze the competitive implications when some consumers can buy both goods. We next analyze the effect of a duopolistic used good market, wherein some consumers purchase both goods.

\section{Case 4: Duopoly with Used Goods}

We are looking for two main insights. First, what is the effect on supplier profits when they are able to sell goods in their competitors' market as well? Second, what will be the required disposable income for consumers to buy both goods? In this section, we proceed to answer these questions by introducing the element of intersupplier competition in the presence of a used good market, because some consumers are willing to buy two goods.

We continue with the stylized scenario of two symmetric suppliers, selling in two different markets of equal size, reduced to a unit mass of one. Based on the strategies outlined below, consumers are segmented into various consumption classes according to their willingness to pay for the good. Recall that in this case, some consumers are interested in buying two goods, one from each supplier, as long as it gives them a positive surplus. This leads to the creation of a new segment, which we term NSN. The dominant consumer strategies and corresponding consumer utility functions are shown below.

1. $\left(N^{i} S N^{j}\right)$ : Buy new good A in period 1 , sell used good in period 2 and buy new good B: $\theta(1+\alpha+\alpha h)-2 P_{d n}^{U^{*}}+\left(1-k_{U}\right) P_{d s^{*}}$.

2. $(N H)$ : Buy new good in period 1 and hold onto the used good in period 2: $\theta(1+h)-P^{U^{*}}{ }_{d n}$.

3. $\left(I U^{i}\right)$ : Remain inactive in period 1 and buy used good in period 2: $\theta q-P_{d s^{*}}$.

4. Remain inactive in both periods: 0 .

Similar to the monopoly case, by equating the incentive-compatibility constraints based on these four strategies, we derive the three indifference points that define the consumer segments in each market, $i$ or $j, i, j \in(A, B)$, which are as follows:

$$
\theta_{1}^{i}=\frac{p_{n}^{j}-\left(1-k_{U}\right) p_{s}^{i}}{\alpha+\alpha h-h} \theta_{2}^{i}=\frac{p_{n}^{i}-p_{s}^{i}}{1+h-q} \theta_{3}^{i}=\frac{p_{s}^{j}}{q}
$$




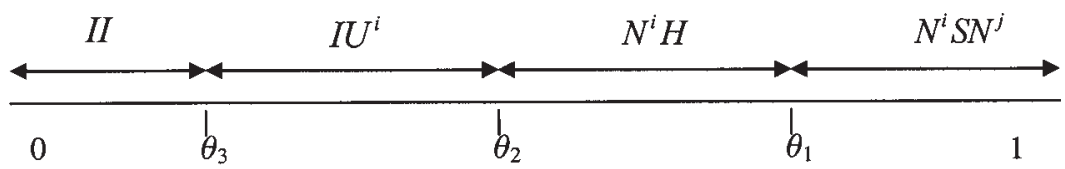

Market $i$

Figure 3. Consumer Consumption Classes in a Duopoly with Used Goods

Note that as before, the grouping of consumers outlined above corresponds directly to their overall valuations of the good. That is, consumers with higher valuations for the good will tend to be on the right, followed by consumers with lower valuations in the middle, and so on toward the left. This is shown in Figure 3. The class division points are derived from the individual-rationality and the incentive-compatibility constraints. Consumers in $\left(1, \theta_{1}{ }^{i}\right)$ will follow $N^{i} S N^{j}$, consumers in $\left(\theta_{1}{ }^{i}, \theta_{2}{ }^{i}\right)$ will follow $N^{i} H$, consumers in $\left(\theta_{2}{ }^{i}, \theta_{3}{ }^{i}\right)$ will follow $I U^{i}$, and those in $\left(\theta_{3}{ }^{i}, 0\right)$ will follow II.

All consumers from 1 to $\theta_{1}{ }^{i}$ are the suppliers of used goods. All consumers from $\left(\theta_{2}{ }^{i}, \theta_{3}{ }^{i}\right)$ create the demand for used goods. By equating the demand of used goods with the supply, we get the market-clearing second period price of used goods $P{ }^{U^{i}}{ }_{d s}$. The optimal new good price, $P^{U^{* i}}{ }_{d n}$, can be derived from the supplier's profit equation, after substituting for $P{ }^{v^{i}}{ }_{d s}$. Note that new good sales occur in the first two segments, that is, in the segments labeled $N^{i} S N^{j}$ and $N^{i} H$. Also, since consumers in $N^{i} S N^{j}$ segment buy from both the suppliers, each supplier also gets the $N^{i} S N^{i}$ segment of the competitor's market. Hence, the supplier's profit is given by

$$
\Pi_{d}^{U}(S)=\left(1-\theta_{1}^{i}\right)\left(1-k_{N}\right) P_{d n}^{U^{i}}+\left(1-\theta_{1}^{j}\right)\left(1-k_{N}\right) P_{d n}^{U^{i}}+\left(\theta_{1}^{i}-\theta_{2}^{i}\right)\left(1-k_{N}\right) P_{d n}^{U^{i}} .
$$

This yields the optimal new good price as

$$
P_{d n}^{U^{* i}}=\frac{2 \alpha+q\left(1-k_{U}-q-h+k_{U} q\right)+h\left(q\left(2-k_{U}-\alpha\right)+4 \alpha-2\right)-2 h^{2}(1-\alpha)}{2(1+\alpha+h \alpha)-k_{U} q} .
$$

The expressions for optimal used price and supplier and retailer profits are given in the Appendix. Before we perform comparative statics, the reader should note that the new good prices and profits are increasing in $\alpha$. This is because a higher $\alpha$ implies that the $N^{i} S N^{j}$ segment is willing to pay more for the good. Formally, we show the following proposition:

Proposition 4 (Competitive New Good Price): The new good prices increase monotonically with $\alpha$, the consumers' degree of preference for the other good, but decrease with the used good commission, $\mathrm{k}_{\mathrm{U}}$. Further, used good prices are increasing with the new good prices.

In a monopolistic scenario, suppliers prefer a high $k_{U}$ because this leads to a smaller used good market, which suits their interests. On the other hand, when some highvaluation customers are willing to buy both the goods, suppliers prefer to have an 
active used good market. This is because the existence of the NSN segment critically depends on the ability of some consumers to sell the used good and extract the extra income from the resale. Proposition 4 shows that $k_{U}$ has an adverse effect on new good prices and profits. This is because with a higher $k_{U}$, consumers get a reduced benefit from selling the used good compared to holding it. Hence the $N H$ segment increases in size whereas the NSN segment shrinks. To compensate for the lower net demand of new goods, the suppliers are forced to reduce their prices to sustain the NSN segment, which, for the most part, reduces their profits. Therefore, unlike the monopoly case, the suppliers now prefer a lower $k_{U}$. On the other hand, the retailer is interested in setting a higher $k_{U}$ in order to extract all the benefits from used good sales. Again, this highlights that retailers and suppliers are incompatible in their incentives in selecting an optimal $k_{U}$. Next, we will show that when the secondary market is modeled as a duopolistic market, suppliers are not necessarily adversely affected. Moreover, new good prices are generally lower in such markets.

\section{Comparative Statics}

\section{Duopoly with Used Good Versus Duopoly Without Used Goods}

ALTHOUGH WE GET CLOSED-FORM SOLUTIONS for the price and profit expressions, the highly nonlinear equations do not yield easy analytical comparisons. Therefore, we use numerical analysis to gain some insight. First, we point out the following:

Observation 1 (Supplier Profit Levels in "Duopolistic" Markets): For all $\alpha \leq$ $\alpha_{\mathrm{m}}$, supplier profits in the duopolistic used good market $\Pi_{\mathrm{d}}^{\mathrm{U}}(\mathrm{S})$ are higher than profits in duopolistic no used good market $\Pi_{\mathrm{d}} \mathrm{N}(\mathrm{S})$.

In other words, when some consumers buy both goods, then there exists an $\alpha_{m}$ such that for $\alpha \in\left[0, \alpha_{m}\right]$, suppliers are better off in the presence of a used good market. To see this, first note that for low $\alpha$, while the prices and profits in a duopolistic market without used goods are very low, this is not necessarily true in a duopolistic used good market. The reason is that the used good market allows consumers to sell their goods, which increases their valuation for a new good. Hence, suppliers can extract this increased valuation by charging somewhat higher prices than in the case without a used good market. This is similar to the notion of "indirect appropriability," as pointed out in the prior literature. ${ }^{12}$

We note that $\Pi_{d}{ }^{U}(S)>\Pi_{d}{ }^{N}(S)$ for low $\alpha$-that is, suppliers are better off with a used good market for lower values of $\alpha$. Conversely, for higher values of $\alpha$, we find that $\Pi_{d}^{U}(S)<\Pi_{d}^{N}(S)$. We first note that at $\alpha=0, \Pi_{d}^{U}(S)>\Pi_{d}^{N}(S)=0$. Next, we note that at $\alpha=1, \Pi_{d}^{U}(S)<\Pi_{d}^{N}(S)=0$. Clearly, if the difference in the profit function under the two scenarios were positive and monotonically increasing, then that would imply the existence of an $\alpha_{m}$, such that suppliers are better off in the presence of a used good market for all $\alpha \leq \alpha_{m}$. Since it is difficult to show this analytically, we use numerical simulations to determine the values of $\alpha_{m}$. 
Observation 2 (Supplier's Prices in the Used Good Market): For all $\alpha \in\left[\alpha_{n}, 1\right]$, suppliers' optimal new good price, $\mathrm{P}_{\mathrm{d}}^{\mathrm{U}}$, in the duopolistic used good market is lower than the price in duopolistic no used good market, $\mathrm{P}_{\mathrm{dn}}$.

We find that for a wide range of $\alpha$, the used goods marketplace actually leads to a decrease in the price of new goods, rather than higher new good prices. One would expect that since suppliers do not gain directly from the sale of used goods, they would necessarily increase the new good prices to extract the maximum surplus from the onetime sale, as previous research has noted [16]. Basically consumers' affinity for the second good induces suppliers to lower the price of the new good to gain additional sales in the competing supplier's market. By lowering their prices, suppliers can now sustain and expand the NSN market segment, thereby accruing a higher profit. We term this the market expansion effect. This brings down the new good prices for a wide range of parameters.

\section{Monopoly with Used Goods Versus Duopoly with Used Goods}

Next, we compare the monopolistic used good market with the duopolistic one.

Proposition 5 (Optimal New Good Price Comparison): For all $\alpha \in\left[\alpha_{\mathrm{dm}}, 1\right]$, suppliers' optimal new good price, $\mathrm{P}_{\mathrm{dn}}^{\mathrm{U}}$, in the duopolistic used good market is higher than the price in the monopolistic used good market, $\mathrm{P}_{\mathrm{mn}}^{\mathrm{u}}$.

Similarly, we point out that for some $\alpha \in\left[\alpha_{c}, 1\right]$, suppliers' profits, $\Pi_{d}{ }^{U}(S)$, in a duopolistic used good market are higher than the monopolistic used good market profits, $\Pi_{m}{ }^{U}(S)$. We know that at very low values of $\alpha$, the new good price, $P_{d n}^{U}$, and profits in a duopolistic market are very low. But the monopolistic price, $P_{m n}^{U}$, and profits do not depend on $\alpha$, and hence they are higher. Moreover, recall from the previous section that in the presence of a duopolistic used good market, new good price, $P_{d n}^{U}$, and profits, $\Pi_{d}{ }^{U}(S)$, are increasing in $\alpha$. Therefore, there exists an $\alpha_{d m}$ such that for $\alpha \in\left[\alpha_{d m}, 1\right], P_{d n}^{U}>P^{U}{ }_{m n}$, and an $\alpha_{c}$ such that for $\alpha \in\left[\alpha_{c}, 1\right], P_{d}^{U}(S)>P_{m}{ }^{U}(S)$.

Basically, intersupplier competition keeps the prices down, whereas the increased valuation keeps the demand up. The $N S N$ segment boosts the demand to a level such that the market expansion effect dominates the price competition effect, leaving suppliers better off even under the duopolistic market structure. In summary, this section highlights the implication of a duopolistic used good market vis-à-vis a monopolistic one (which has been commonly studied in literature). The important economic effect of competition in a secondary market is that it creates a segment of consumers, $N^{i} S N^{j}$, who are willing to buy their less preferred, but additional, new good due to their increased valuation for a good. Segmenting the market lowers the average cost of owning (or renting) a good, thus creating more buyers. In effect, the used good option is like a rebate coupon that reduces the net price consumers actually pay for the new good. The purchase price of a new good effectively becomes equal to the discounted sum of two prices- the new good price in period 1 minus the expected used good price in period 2. 


\section{Empirical Evidence}

OUR ANALYTICAL MODEL PROVIDES us with two testable assertions. First, we show that an increase in the availability of used goods leads to a decrease in the new good price. Prior work and conventional wisdom suggests that opening a used good market would lead to an increase in new good prices. Irrespective of the value of the holding utility, $h$, once the effect of duopolistic competition is taken into account, new good prices need not increase with the establishment of secondary markets. Second, we show that the used good price increases in the new good price.

The online book market provides a rich arena to test the robustness of these two results. It is one of the fastest growing industries on the Internet. Online book sales grew from essentially nothing in 1995 to more than $\$ 2.5$ billion in 2003 [18]. Today, such sales make up between 7.5 percent and 10 percent of total book sales in the United States. Our data set is compiled from publicly available information on new and used book prices on Amazon.com. The data is gathered using automated Java bots to download and parse HTML pages from Amazon.

The data were collected in two separate samples. The first was collected from September 2002 to March 2003, and the second was collected between April and July 2004. Our total data set includes approximately 400 individual book titles. This panel of books includes an equal number of books from each of five major categories: New York Times (NYT) best sellers, former NYT best sellers, Amazon best-seller computer books, best-selling textbooks, and "new and upcoming books." Current best sellers were included because of their popularity, high sales, and their relevance to publisher price discrimination strategies (using phased releases of binding types). We randomly selected books appearing in the NYT best-sellers list. Using the LexisNexis database, we included a sample of $N Y T$ best sellers from 1999 to analyze the effect of time on the availability and pricing of used books. Former best sellers should have a larger base of copies in circulation than other titles, potentially increasing the number of used copies for sale. Best-selling computer books represent one of the most popular book categories sold online, and are also subject to demand shocks based on the version updates over time and changes in technology. Our best-selling computer books were selected at random from the best-seller list at Amazon. Textbooks, which are also included in our survey, have similar demand characteristics to computer booksboth in terms of popularity and demand shocks. Our textbooks are selected at random from facultyonline.com best sellers. Our final category is new and upcoming books. This category allows us to examine the development of used book markets for recent releases over a period of time. Our total data sample includes 41,994 observations.

For each of the books we tracked that is uniquely identified by an International Standard Book Number (ISBN), we collect data on new book prices charged by Amazon, as well as new and used book prices among Amazon marketplace sellers. Besides prices, for each offer listed, we collect the book's self-reported condition, and the seller's marketplace rating (a star rating provided by prior customers). Our control variables include the log of the time since the book was released (Datediff), the condition of the lowest-priced used book (Condition), the seller rating for the 
Table 1. Parameter Estimates for the $P_{A N}$ and $P_{U s e d M i n}$ Models

\begin{tabular}{|c|c|c|}
\hline Variable & $\begin{array}{c}\text { Dependent } \\
\text { variable } P_{A N}\end{array}$ & $\begin{array}{c}\text { Dependent } \\
\text { variable } P_{U s e d M i n}\end{array}$ \\
\hline Constant & $\begin{array}{c}2.9^{\star \star \star} \\
(158.0)\end{array}$ & $\begin{array}{l}2.83^{\star \star \star} \\
(33.7)\end{array}$ \\
\hline$P_{A N}$ & - & $\begin{array}{c}0.38^{* * *} \\
(15.28)\end{array}$ \\
\hline$P_{\text {NAN }}$ & $\begin{array}{l}0.02^{\text {***}} \\
(6.6)\end{array}$ & $\begin{array}{l}0.13^{\star * *} \\
(7.65)\end{array}$ \\
\hline$P_{\text {UsedMin }}$ & $\begin{array}{l}0.016^{* *} \\
(15.68)\end{array}$ & - \\
\hline CountofUsed & $\begin{array}{l}-0.004^{\star * \star} \\
(-3.72)\end{array}$ & $\begin{array}{l}-0.075^{\star * *} \\
(-11.5)\end{array}$ \\
\hline SellerRating & $\begin{array}{l}0002 \\
\quad(0.363)\end{array}$ & $\begin{array}{l}0005 \\
(0.43)\end{array}$ \\
\hline Condition & $\begin{array}{l}-002^{* * *} \\
(-2.34)\end{array}$ & $\begin{array}{l}-0.013^{\text {***}} \\
(-5.6)\end{array}$ \\
\hline Datediff & $\begin{array}{l}-0.017^{\star \star \star} \\
(-10.65)\end{array}$ & $\begin{array}{l}-0.35^{\star \star \star} \\
(-44.1)\end{array}$ \\
\hline$R^{2}$ & 0.45 & 0.37 \\
\hline
\end{tabular}

Notes: The $t$-statistics are given in parentheses. Using a log linear functional form to estimate this regression gives qualitatively similar results. $<<$ note for $* * *$ and $* *>>$

lowest-priced used book (SellerRating), and the log of the number of used books offered for sale for a particular book (CountofUsed). Since Amazon provides four different conditions (or quality) levels of used books (like new, very good, good, and acceptable), our data include all used book offers on a given date for each condition. Clearly, since including each used book offer in our regression is impractical, from the set of offers we selected the minimum price for each of these four possible conditions of a given used book. This was done because the minimum price for a specific condition of a used book strictly dominates any other price offers at that condition. Thus we derived four new variables constituting the minimum prices of used books, denoted by $P_{U s e d} i(i \in[2,5])$ in Table 1 , which contains the summary statistics for our data. Formally, we use the following terminology: Used 2 for a book of quality "like new," Used 3 for quality "very good," Used4 for quality "good," and Used5 for a book of "acceptable" quality. Finally, we also derived the minimum price on a given day for all offered used books (across all conditions) and denote it as $P_{\text {UsedMin }}$. We denote the quality of a used book by the variable Condition. Note that given the manner in which we code the Condition variable, an increase in condition denotes a decrease in the used book quality.

Table 2 lists summary statistics for our data. All prices listed are the lowest prices for each category for each ISBN. We did this because many of the used and new nonAmazon prices in our data set were substantially higher than the lowest price for the same condition listed for the same book on the same date. 
Table 2. Guide to Notations

\begin{tabular}{|c|c|}
\hline Variable & Interpretation \\
\hline$\theta$ & Consumer types uniformly distributed between $(0,1)$. \\
\hline$\theta_{i}$ & Market share cutoff of firm $i$ where $i \in(1,2)$ \\
\hline$D_{i}$ & Market demand of firm $i$ from good $j$ where $j \in(A, B)$. \\
\hline$q$ & Utility from buying a used good for type $\theta$. \\
\hline$h$ & Utility from holding a used good for type $\theta$. \\
\hline$\alpha$ & Cross-product purchase affinity for a consumer. \\
\hline$k_{N}$ & New good commission charged by supplier. \\
\hline$k_{u}$ & Used good commission charge by retailer. \\
\hline$S_{A}, S_{B}$ & Supplier A and B, respectively. \\
\hline$N$ & A single-period action of buying a new good. \\
\hline$H$ & A single-period action of holding onto a used good. \\
\hline$S$ & A single-period action of selling a used good. \\
\hline$U$ & A single-period action of buying a used good. \\
\hline I & A single-period action of remaining inactive. \\
\hline$P^{N_{m n}^{i}}$ & New good price of supplier $i$ in a monopoly without used goods. \\
\hline$P^{N}{ }_{d n}^{i n}$ & New good price supplier $i$ in a duopoly without used goods. \\
\hline$P_{m n}^{U}$ & New good price in a monopoly with used goods. \\
\hline$P_{d n}^{u}$ & New good price in a duopoly with used goods. \\
\hline$P_{m s}^{U}$ & Used good price in a monopoly. \\
\hline$P v_{d s}^{\prime \prime}$ & Used good price in a duopoly. \\
\hline$\Pi_{m}^{N}(S)$ & Supplier profit in a monopoly without used goods. \\
\hline$\Pi_{d}^{N}(S)$ & Supplier profit in a duopoly without used goods. \\
\hline$\Pi_{m} \cup(S)$ & Supplier profit in a monopoly with used goods. \\
\hline$\Pi_{d} \cup(S)$ & Supplier profit in a duopoly with used goods. \\
\hline$\Pi_{m}^{N}(R)$ & Retailer profit in a monopoly without used goods. \\
\hline$\Pi_{d}^{N}(R)$ & Retailer profit in a duopoly without used goods. \\
\hline$\Pi_{m} \cup(R)$ & Retailer profit in a monopoly with used goods. \\
\hline$\Pi_{d} \cup(R)$ & Retailer profit in a duopoly with used goods. \\
\hline
\end{tabular}

Based on the propositions developed in earlier sections, we have the following two testable hypotheses.

Hypothesis 1 (Used Good Secondary Market Availability): An increase in the availability of used goods in a secondary market leads to a decrease in the new good prices.

Hypothesis 2 (New Good-Used Good Price Increase): Given the presence of used books, all else being equal, an increase in the new good price leads to an increase in the used good price.

To test the first assertion, we compare new book prices with changes in the availability of used books. Fortunately, in our data, there are a significant number of observations for both scenarios: when there are many used books offered and when there are fewer used books offered. Therefore, we estimate

$$
P_{A N_{b t}}=\beta_{1} P_{N A N_{b t}}+\beta_{2} P_{U_{\text {sedMin }} b t}+\beta_{3} \text { CountofUsed }_{b t-1}+\beta_{4} X_{b t}+\varepsilon_{b t} .
$$


Given the nature of our data (cross-sectional plus time series) we use a fixed effects regression model to test our hypothesis. ${ }^{13}$ The second hypothesis claims that, given the presence of used books, used book prices are higher when new books are priced higher. To alleviate any endogeneity concerns, we ran the following regression using lagged values (by time period).

$$
\begin{gathered}
P_{\text {UsedMin }_{b t}}=\gamma_{1} P_{A N_{b(t-1)}}+\gamma_{2} P_{N A N_{b(t-1)}}+\gamma_{3} \text { CountofUsed }_{b(t-1)} \\
+\gamma_{4} X_{b(t-1)}+\varepsilon_{b(t-1)}
\end{gathered}
$$

The variables are indexed by book, $b$, and time, $t$. In Equation (8), the independent variables are a vector of "new" non-Amazon marketplace prices $P_{N A N}$, a vector of Amazon marketplace prices $P_{\text {UsedMin }}$, a vector of the number of used goods available, and a vector of other control variables $(X)$. In Equation (9), the independent variables are Amazon price $P_{A N}$, a vector of "new" non-Amazon marketplace prices $P_{N A N}$, a vector of the number of used goods available, and a vector of other control variables $(X)$. Since we estimate a fixed-effects model, book-specific idiosyncrasies are captured in the fixed-effect constant. The estimates are presented in Table 3.

The data supports Hypotheses 1 and 2. In Equation (8), the coefficients of the variable, CountofUsed is negative and significant, indicating that the increase in the availability of a used book leads to lower new book prices. Further, in Equation (9), the coefficient of the term $P_{A N}$ is positive, implying that if the new book price increases, then the used book price also increases.

\section{Conclusion}

THE ONGOING HEATED DEBATE BETWEEN suppliers and retailers has focused on the supposed damage that secondary markets established by online retailers are inflicting on royalty payments and supplier profits. Amazon's secondary market is flourishing, with more consumers discovering that buying used information goods, such as books, CDs, videos, and DVDs, could lead to significant cost savings. However, the general consensus is that used good sales cannibalize new good sales and, consequently, are harmful to suppliers, thereby ruling out the possibility of harmonious coexistence for all traditional players in these markets.

Using a game-theoretic model, we investigate the competitive implications of these newly emerging secondary markets on supply-chain profits and new good prices. We show that the major motivation of the retailer to establish a used good market is to capture additional surplus from those consumers who were unable to buy in the new good market. This enables the retailer to effectively practice quality-based price discrimination at no additional cost. Our model also highlights that unlike a monopolistic market, intersupplier competition can be beneficial to suppliers in the presence of a secondary market, rather than harmful. This occurs because the presence of used goods subdues the rate at which suppliers can increase the new good prices with consumers' cross-product purchase affinity. This factor affects the market in such a 
Table 3. Summary Statistics

\begin{tabular}{lrrcr}
\hline Variable & Mean & $\begin{array}{c}\text { Standard } \\
\text { deviation }\end{array}$ & Minimum & Maximum \\
\hline$P_{\text {AN }}$ & 24.16 & 26.17 & 1.95 & 209.99 \\
$P_{\text {NAN }}$ (lise new) & 17.74 & 23.08 & 0.01 & 209.99 \\
$P_{\text {Used }}$ (lve & 15.71 & 21.98 & 0.01 & 194.28 \\
$P_{\text {Used }}$ (very good) & 11.26 & 20.82 & 0.01 & 207.60 \\
$P_{\text {Used4 }}$ (good) & 11.24 & 17.44 & 0.01 & 200.00 \\
$P_{\text {Used }}$ (acceptable) & 7.86 & 17.13 & 0.01 & 222.25 \\
$P_{\text {UsedMin }}$ (all conditions) & 13.14 & 19.15 & 0.01 & 151.95 \\
CountofUsed & 81.15 & 131.78 & 1 & 753 \\
SellerRating & 3.97 & 1.65 & 0 & 5 \\
Condition & 2.33 & 1.14 & 1 & 5 \\
Datediff & 717.7 & $1,336.22$ & 0 & 21,235 \\
\hline
\end{tabular}

way that the market expansion effect compensates for the price competition effect. Thus, we show that contrary to popular perceptions, the presence of a used good market is beneficial for suppliers, too, under a relatively wide range of conditions. When merchandized as a deep discount option to an otherwise inflated new good price, electronic secondary markets offer consumers an extremely attractive option to increase their valuation for a new good, thereby spurring additional new good sales.

In sum, the insights from this model help to explain several interesting market phenomena, including (1) the profitability of concurrent sales of new and used goods for suppliers - that is, why secondary markets may not be detrimental for them if one considers the market expansion effect; (2) the possibility of lower new good prices when there are secondary markets, under both monopolistic and competitive scenarios; and (3) the strategic role of used goods commission fees and their differential impact on equilibrium prices and profits for suppliers and retailers, under monopolistic and duopolistic markets. Using data from Amazon, we test two of our assertions from the analytic model and also provide empirical estimates of the effect of an electronic secondary market on new book prices.

Our analysis has implications for suppliers who sell through intermediaries but cannot appropriate direct gains from secondary markets. As long as there is more than one supplier, and consumers are willing to buy another new good, a secondary market can be beneficial for suppliers. Thus, there may be significant gains in producer welfare from the additional sales. Indeed, retailers, such as Amazon, and suppliers such as book publishers as well as movie studios and record labels, stand to benefit and earn a slice of the growing pie created by lower search and transactions costs of electronic secondary markets. As more consumers migrate online and adopt such resale practices, this indirect market expansion effect can further alleviate the damages incurred by suppliers from the direct effect of cannibalization of new good by used goods. 
Another implication from our model is that while deriving their optimal pricing strategies, suppliers need to keep in mind the effect of a positive holding utility that some consumers derive from keeping their used goods, instead of necessarily selling them. This is especially true in the case of music CDs or textbooks where consumers are likely to listen to a song or read the book repeatedly, compared to a fiction book or a DVD whose utility diminishes at a much faster rate. Ignoring this aspect of consumer behavior will erroneously drive up the price beyond the optimal value. Further, this caveat also holds true for a retailer deriving its optimal used good commission, because the extent to which a retailer benefits from establishing a secondary market is dependent on it. As pointed out earlier, the retailer's optimal used good commission is a function of the extent of quality degradation and the value that buyers derive from holding the used good through the course of its life. It is conceivable that these parameters vary among information goods, and the broader context of durable goods in general. So, careful consideration needs to be given by the retailer while fixing its commissions due to its strong effect on consumers' buying and selling patterns. From the supplier's perspective, the used good commission is critical due to its interdependency with new good commission.

One limitation of our model is that we do not consider more than two suppliers and that we do not consider an $n$-period model. However, our intuition is that the main effect of cross-product purchase affinity $(\alpha)$ driving our results on prices and profits carry through with multiple suppliers or multiple periods. A preliminary analysis reveals that incorporating multiple suppliers or multiple resale periods only restricts the space of $\alpha$ where the supplier benefits from used good markets. Another interesting extension would be to incorporate consumer heterogeneity in a second dimension, such as by introducing a distribution for the quality degradation parameter, $q$. In such a scenario, rather than all used good sellers selling goods at the same quality, $q$, there would be a distribution that characterizes the seller-specific degradation of the quality of the good. We hope that our study inspires more interest and paves the way for these future explorations.

Acknowledgments: The authors are grateful to Uday Rajan for insightful feedback and Rob Kauffman for detailed suggestions. They thank Erik Brynjolfsson, Anthony Dukes, seminar participants at Carnegie Mellon University, and participants at the Marketing Science 2003 Conference, International Conference on Information Systems (ICIS) 2003, Workshop on Information Systems and Economics (WISE) 2004, and Hawaii International Conference on System Sciences (HICSS) 2005 for helpful comments. Finally, they thank the AE and two anonymous reviewers for their suggestions. This work was supported in part by a grant from the National Science Foundation (NSF IIS-0118767). All errors are the authors' responsibility.

\section{NoTES}

1. The problem arises because durable goods sold in the future affect the future value of units sold today, and, in the absence of the ability to commit, the monopolist does not internalize this externality. Having sold a certain quantity, a firm still faces a residual demand for the good, consisting of those consumers who place a value on the good lower than the current 
market price. As a result, the firm has an incentive to lower its price to attract these customers. But rational consumers factor in future price reductions into their current willingness-to-pay.

2. We use the terms secondary market and used good market interchangeably in this paper.

3. We use the term duopolistic to denote the fact that there are two firms competing in the market, but only for a subset of the consumers who are willing to buy more than one good. Similarly, we will use the term monopolistic to denote the fact that neither firm faces any competition in its market.

4. In our model, the suppliers choose the new good price. In the traditional channel literature with a decentralized distribution structure, allowing the retailer to choose the price leads to the well-known double marginalization problem and results in an increase in new price by an amount proportional to the wholesale price [20]. Because the used prices are determined by market-clearing conditions, this leads to an increase in the used price as well. As a result, the qualitative nature of our results remain unchanged.

5. This eventually results in both suppliers selling in each market, which makes this case less attractive for us to analyze.

6. We do not consider the channel coordination issues as it is not the focus of this paper. There is a large literature on channel coordination mechanisms in marketing and operations for the supply chain or sale channel, using tools such as "return policies" or "buy-back policies." See for example, Cachon [7].

7. A comparison of the supplier profits reveals that for all $\alpha<0.33$, suppliers are better off under a duopoly compared to a monopoly. However, since our main focus is on how used good markets affect supply-chain profitability, we do not analyze this case in detail.

8. This is similar to the approach taken by Desai and Purohit [9]. Unlike their model, where the manufacturer chooses optimal quantities, in our model, the suppliers choose optimal prices.

9. This implies that below this cutoff value of $h$, the suppliers would find it profitable not to have the $N H$ segment. We derive this cutoff value of $h$ in the Appendix and show that it is quite low for the whole range of used quality parameter $q$.

10. Note that prior research by Rust [19] has indicated that used good markets will cause new good prices to increase. In our model, if consumers are unwilling to pay suppliers for second-period utility (i.e., if $h$ is equal to zero), then the new good price is $p_{n}{ }^{*}=\left(1+q-k_{q}\right) / 2$, as shown in the Appendix. Hence, in our model as well, opening a used good market results in the new good price increasing from $1 / 2$ to $p_{n}{ }^{*}$, which is consistent with prior findings.

11. Proof of Proposition 3 has been omitted in the Appendix, because it is immediate.

12. With indirect appropriability, the seller can extract all the rents from a user by charging a higher price for the original because the total willingness-to-pay for the whole is higher.

13. We ran the same regression using dummy variables for capturing information on book types - that is, we used dummies for fiction books, nonfiction books, hardcovers, paperbacks, textbooks, best sellers, former best sellers, and computer books. These serve as control variables in addition to Datediff. Again, there was no qualitative change in the results.

\section{REFERENCES}

1. Anderson, S., and Ginsburgh, V. Price discrimination by second-hand markets. European Economic Review, $38<<$ issue and/or season>> (1994), 23-44.

2. Aron, R., and Sundararajan, A. An economic analysis of electronic secondary markets: Installed base, technology, durability and firm profitability. Decision Support Systems, 24 (December 1998), 3-16.

3. Bakos, Y. Reducing buyer search costs: Implications for electronic marketplaces. Management Science, 43, 12 (1997), 1676-1692.

4. Benjamin, D., and Kormendi, R. The interrelationship between the markets for used and new durable goods. Journal of Law and Economics, <<volume / issue >> (October 1974), 381401.

5. Bond, E., and Samuelson, L. Durable good monopolies with rational expectations and replacement sales. Rand Journal of Economics, 15, 3 (1984) 336-345.

6. Bulow, J. Durable-goods monopolist. Journal of Political Economy, 90, 2 (1982), 314-322. 
7. Cachon, G. Supply chain coordination with contracts. In S. Graves and T. de Kok (eds.), The Handbook of Operations Research and Management Science: Supply Chain Management. Amsterdam: Kluwer, 2003, <<page range >>.

8. Coase, R. Durability and monopoly. Journal of Law and Economics, $15<<$ issue and/or season $>>$ (1972), 143-149.

9. Desai, P., and Purohit, D. Leasing and selling: Optimal marketing strategies for a durable goods firm. Management Science, 44, 11 (1998), 19-34.

10. Genesove, D. Adverse selection in the wholesale used car market. Journal of Political Economy, 101, 4 (August 1993), 644-665.

11. Geoffrion, A., and Krishnan, R. Prospects for operations research in the e-business era. Interfaces, 31, 2 (2001), 6-36.

12. Ghose, A.; Smith, M.; and Telang, R. Internet exchanges for used books: Welfare implications and policy issues. Working Paper, New York University and Carnegie Mellon University, 2004.

13. Hendel, I., and Lizzeri, A. Interfering with secondary markets. Rand Journal of Economics, 30, 1 (Spring 1999), 1-20.

14. Kahn, C. The durable goods monopolist and consistency with increasing costs. Econometrica, 54, 2 (March 1986), 275-294.

15. Liebowitz, S. Durability, market structure and new-used goods models. American Economic Review, 72, 4 (1982), 816-824.

16. Miller, H. On killing off the market for used textbooks and the relationship between markets for new and secondhand goods. Journal of Political Economy, 82, 3 (1974), 612-619.

17. Porter, R.H., and Sattler, P. Patterns of trade in the market for used durables: Theory and evidence. National Bureau of Economic Research Working Paper 7149, Cambridge, MA, 1999.

18. Rosenthal, M. North American book market. <<organization / location >> (available at www.fonerbooks.com, accessed on April 10, 2005). $<<$ web site states "hebrew translations on demand" -- where can specific page be found?>>

19. Rust, J. When is it optimal to kill off the market for used durable goods? Econometrica, 54, 1 (1986), 65-86.

20. Stern, L.; Ansari, E.; and Coughlan, A. Marketing Channels, 5th ed. Upper Saddle River, NJ: <<publisher >>, 1988.

21. Takeyama, L. The welfare implications of unauthorized reproduction of intellectual property in the presence of externalities. Journal of Industrial Economics, 62, 6 (1994), 155-166.

22. Waldman, M. Eliminating the market for secondhand goods: An alternative explanation for leasing. Journal of Law and Economics, 40, 1 (1997), 61-92.

23. Waldman, M. Durable goods theory for real world markets. Journal of Economics Perspectives, 17, 1 (2003), 131-154.

24. Wingfield, N. The other eBay: Amazon is winning over small vendors. Wall Street Journal (July 22, 2002), B1. 


\section{Appendix}

\section{Proof of Lemma 1 (Monopoly Prices Without Used Goods)}

WE SHOW AN UPPER LIMIT OF $\alpha$ such that beyond that value, a supplier would no longer offer the monopoly price. Suppose one supplier, say $S_{A}$ (selling good A), decides to deviate from its monopoly price $P^{N}{ }_{m n}$ to $P_{1}$, and get some type B users to buy good A. It is immediate to show the demand $D_{1}{ }^{A}$ for good A from type A consumers at $P_{1}$ is $1-\theta_{1}{ }^{A}=1-\left(P_{1} /(1+h)\right)$.

Due to the lower price charged by $S_{A}$, some consumers in a type B market will find it incentive compatible to buy good $\mathrm{A}$, as long as it satisfies their individual-rationality constraints. Hence, the type B market splits into two segments, such that high $\theta$ consumers buy their preferred good B, while remaining buyers purchase good A. Therefore, we have

$$
\theta_{1}^{B}(1+h)-P_{m n}^{N} \geq \alpha \theta_{1}^{B}(1+h)-P_{1} \alpha \theta_{2}^{B}(1+h)-P_{1} \geq 0,
$$

where $\theta_{1}{ }^{B}$ is the consumer indifferent between buying good $\mathrm{B}$ and good $A$, whereas $\theta_{2}{ }^{B}$ is the consumer indifferent between buying good $\mathrm{A}$ and not buying at all. From this, we have

$$
\theta_{1}^{B}=\frac{P_{m n}^{N}-P_{1}}{(1+h)(1-\alpha)}, \theta_{2}^{B}=\frac{P_{1}}{\alpha(1+h)}
$$

Now all type B consumers between $\theta_{1}{ }^{B}$ and $\theta_{2}{ }^{B}$ buy from $S_{A}$. Hence, demand $D_{1}{ }^{B}$ for good A in a type B market at $P_{1}$ is

$$
D_{1}^{B}=\theta_{1}^{B}-\theta_{1}^{A}=\frac{\alpha P_{m n}^{N}-P_{1}}{\alpha(1-\alpha)(1+h)} .
$$

Thus, the total demand for $S_{A}$ is given by the demand from its own market and from a portion of its competitor's market. Therefore, total demand is $D\left(P_{1}\right)=D_{1}{ }^{A}+D_{1}{ }^{B}$. Hence, the profit is given by

$$
\Pi^{A}(S)=P_{1}\left(1-k_{N}\right)\left[\frac{1}{(1+h)}\left\{\frac{\left(\alpha P_{m n}^{N}-P_{1}\right)}{\alpha(1-\alpha)}-P_{1}\right\}+1\right]
$$

Optimizing Equation (A2) after substituting the monopoly price $P^{N}{ }_{m n}$ gives us the optimal price $P_{1}{ }^{*}=(\alpha(3-2 \alpha)(1+h)) /(4(1+(1-\alpha) \alpha))$. Substituting $P_{1}^{*}$ in Equation (A2), we get the optimal supplier profit:

$$
\Pi^{A}(S)=\left(1-k_{N}\right) \frac{(3-2 \alpha)^{2} \alpha(1+h)}{16(1-\alpha)^{2}} .
$$


Comparing this with monopoly profits given by Equation (1) and solving for $\alpha$ provides the critical value of $\alpha=0.61$, beyond which $S_{A}$ finds it profitable to offer $P_{1}{ }^{*}$. It is trivial to show that the deviated price $P_{1}^{*}<P^{N}{ }_{m n}$ as one would expect by construction.

\section{Proof of Lemma 2 (Duopoly Prices Without Used Goods)}

Consider the equilibrium in which some consumers are willing to buy both goods. Suppose supplier $S_{A}$ charges a price $P^{N^{A}}{ }_{d n}$ and supplier $S_{B}$ charges a price $P^{N^{B}}{ }_{d n}$. Consider $S_{A}$ 's market. From the individual-rationality and the incentive-compatibility constraints, we get the consumer in $S_{A}$ 's market who is indifferent between buying both $\operatorname{good} \mathrm{A}$ and $\mathrm{B}$, or only good $\mathrm{A}$ as

$$
\theta_{1}^{A}(1+h)-P_{d n}^{N^{A}}+\alpha \theta_{1}^{A}(1+h)-P_{d n}^{N^{B}} \geq \theta_{1}^{A}(1+h)-P_{d n}^{N^{A}}
$$

Similarly, the consumer indifferent between buying good A and not buying at all is given by

$$
\theta_{2}^{A}(1+h)-P_{d n}^{N^{A}} \geq 0
$$

From Equations (A4) and (A5), we have the following cutoffs:

$$
\theta_{1}^{A}=\frac{P_{d n}^{N^{B}}}{\alpha(1+h)}, \theta_{2}^{A}=\frac{P_{d n}^{N^{A}}}{1+h} .
$$

Now, total demand for $S_{A}$ is given by $D\left(P_{N^{A}}, P_{N^{B}}^{B}\right)=D_{1}^{A}$ (demand in its own market) $+D_{1}^{B}$ (demand in $S_{B}$ 's market). Hence, the profit for $S_{A}$ is $\Pi_{A}(S)=P_{d n}^{N^{A}}(1-$ $\left.\theta_{2}^{A}\right)+P^{N^{B}}{ }_{d n}\left(1-\theta_{1}{ }^{B}\right)$. From this, the profit-maximizing price $P^{N^{*}}{ }_{d n}$ is $(\alpha(1+h)) /(1+\alpha)$. Profit at this price is also $\Pi_{A}(S)=(\alpha(1+h)) /(1+\alpha)$. By symmetry, the optimal price of $S_{B}$ is also $(\alpha(1+h)) /(1+\alpha)$ and profit is equal to $\Pi_{B}(S)=(\alpha(1+h)) /(1+\alpha)$.

\section{Proof of Proposition 1 (New Good Price and Supply-Chain Profits)}

We have assumed that the holding utility $h$ is high enough for the $N H$ segment to exist. Recall that these are the consumers who buy a new good in period 1 and then hold onto the used good in period 2. We now proceed to derive the critical value of $h$ below which the supplier will price the new good in a way such that the $\mathrm{NH}$ segment does not exist. In particular, for the $\mathrm{NH}$ segment to exist, it must be that the utility that the agent with $\theta=1$ obtains from buying the new good at time 1 and holding it at time 2 strictly exceeds the utility from buying the new good at time 1 and selling it at time 2. That is,

$$
1-P_{m n}^{U}+h \geq 1-P_{m n}^{U}+\left(1-k_{U}\right) P_{m s}^{U}
$$


or $P_{m s}^{U}<h /\left(1-k_{U}\right)$. Otherwise, there is no $N H$ segment. Suppose $P_{m s}^{U}>h /\left(1-k_{U}\right)$. Then $\theta 1=\left(P_{m n}^{U}-\left(2-k_{U}\right) P_{m s}^{U}\right) /(1-q)$ and $\theta_{2}=P_{m s}^{U} / q$. From the market-clearing condition, we find that

$$
P_{m s}^{U}=\frac{q\left(2 P_{m n}^{U}-1+q\right)}{\left(1+q\left(3-2 k_{U}\right)\right)} .
$$

Plugging this back in the supplier's profit equation and maximizing it with respect to the new good price, this gives the optimal new good price

$$
P_{m n}^{U}=\frac{\left(1+q-k_{U} q\right)}{2}
$$

This proves that in the absence of the $\mathrm{NH}$ segment- that is, when no consumer derives any positive utility from holding the used good-the new good price increases in the presence of the secondary market. From this, supplier profits turn out to be

$$
\frac{\left(1-k_{N}\right)\left(1+\left(1-k_{U}\right) q\right)^{2}}{4+4\left(3-2 k_{U}\right) q} \text {. }
$$

Comparing this with the supplier profits when there is an $\mathrm{NH}$ segment, we find that the critical value of $h$ is given by $\left(q^{2}\left(2+k_{U}^{2}-3 k_{U}\right)\right) /\left(2+4 q-3 k_{U} q\right)$. For any value of $h$ above this, the supplier will find it profitable for the $N H$ segment to exist. A numerical analysis reveals that for $k_{U}=0.15$ and $q \in(0,1)$, the critical value of $h$ ranges from $(0.01,0.25)$. Thus, for a wide region in the parameter space, it is optimal for the supplier to price the new good in a way that ensures the existence of the $\mathrm{NH}$ segment.

1. Comparing the prices of the new good with and without used good markets, we find that prices in the absence of used goods markets $\Pi_{m n}^{N}(S)$ will be higher than that with used goods markets $\Pi_{m n}^{U}(S)$ if and only if

$$
\frac{(q-h)\left(\left(1-k_{U}\right) q-h\right)}{2\left(h+q-k_{U} q\right)}>0 .
$$

Recall that $\left(1-k_{U}\right) q>h$. Hence, this expression is positive.

2. Comparing the profits of the supplier with and without used good markets, we find that profits in the absence of used goods markets $\Pi_{m}{ }^{N}(S)$ will be higher than those with used goods markets $P_{m}{ }^{U}(S)$ if and only if

$$
\frac{\left(1-k_{N}\right)(q-h)\left(\left(1-k_{U}\right) q-h\right)}{4\left(h+q-k_{U} q\right)}>0 .
$$

Since $\left(1-k_{U}\right) q>h$, this expression is positive. 
Comparing the profits of the retailer with and without used good markets, we find that profits in the presence of used good markets $\Pi_{m}{ }^{U}(R)$ will be higher than those without used goods markets $\Pi_{m}{ }^{N}(R)$ if and only if

$$
\frac{\left(\left(1-k_{U}\right) q-h\right)\left(\left(2-k_{N}\right) h k_{U} q-h^{2} k_{N}-\left(1-k_{U}\right) k_{N} q\right)}{4\left(h+q-k_{U} q\right)^{2}}
$$

is positive. Since $\left(1-k_{U}\right) q>h$, this implies that the first term in the previous expression is positive. Solving for the value of $k_{U}$, which makes the second term positive also, it is easy to show that this critical value is given by $k_{U} \geq\left(k_{N}\left(q^{2}-h^{2}\right)\right) /(q((2-$ $\left.\left.k_{N}\right) h+k_{N} q\right)$ ).

\section{Proof of Proposition 2 (Effect of Used Good Commission on Prices)}

Recall Equations (2) and (4), which give the new good prices set by the supplier and optimal supplier profits. With some algebraic simplification, it can be shown that the first-order derivatives and their corresponding signs reduce to the following expression.

$$
\frac{d P_{m s}^{U}}{d k_{U}}=\frac{h q^{2}}{\left(h+q-k_{U} q\right)^{2}}>0 \frac{d P_{m n}^{U}}{d k_{U}}=h q(q-h)\left(h+q-k_{U} q\right)^{2}>0 .
$$

\section{Proof of Proposition 4 (Competitive New Good Price)}

First, we outline all possible strategies. Apart from the four strategies stated in the Proposition 4, consumers could adopt the following two strategies: NSU and IN. We show that both strategies are dominated by others. (1) Utility from following an NSU strategy $U^{N S U}=\theta(1+\alpha h)-P_{d n}^{U}-P_{d s}^{U}+\left(1-k_{U}\right) P_{d s}^{U}$. (2) Utility from following an $I N$ strategy $U^{I N}=\theta(1+h)-P_{d n}^{U}$.

Comparing $N H$ and $N S U$, we find that $U^{N H}-U^{N S U}=\theta(h-\alpha h)+k_{U} P_{d s}^{U}>0$. Hence, $N S U \leq N H$. Also, utility from $I N=\theta(1+h)-P_{d n}^{U}$, which is the same as that from $N H$. Since buying a particular new good in either period gives the consumer the same utility, it is reasonable to assume that consumers prefer buying it in the first period rather than the second period. This is like a tie-breaking rule. Hence, all consumers prefer $N H$ to IN. This leads to the four possible strategies as stated in Proposition 4. From the demand-supply clearance condition for used goods, we get

$$
P_{d s}^{U_{1}}-\frac{-1+\frac{P_{d n}^{U_{1}}}{1+h-q}+\frac{P_{d n}^{U_{2}}}{\alpha-h(1-\alpha)}}{\frac{1}{1+h-q}+\frac{1}{q}+\frac{1-k_{U}}{\alpha-h(1-\alpha)}}=0
$$


Similarly, we get $P_{d s}^{U_{2}}\left(P_{d n}^{U_{2}}, P^{U_{1}}\right)$. Plugging these back into the suppliers' profit Equation (6) and maximizing it w.r.t. price $P^{U_{1}}$, we get the reaction function

$$
P_{d n}^{U_{1}}\left(P_{d n}^{U_{2}}\right)=\frac{1}{2}\left(2+2 h-q+\frac{\left(k_{U}\left(1+h-P_{d n}^{U_{2}}\right)+2\left(P_{d n}^{U_{2}}\right)\right) q-2(1+h)^{2}}{1+q\left(1-k_{U}\right)+\alpha(1+h)}\right)
$$

Similarly, we get the reaction function for the other supplier $P^{U_{2}}\left(P_{d n}^{U_{1}}\right)$. Solving these two reaction functions simultaneously gives us the optimal new good price $P^{U^{*}}{ }_{d n}$, given by Equation (7). From this and Equation (A6), we get the optimal used price:

$$
\begin{aligned}
& P_{d s}^{U^{*}}= \\
& \frac{q^{2}\left(\left(1-k_{U}\right)(1-q)^{2}-\alpha^{2}+h^{2}\left((2-\alpha) \alpha+k_{U}-2\right)-2 h\left(\left(1-k_{U}\right)(1-q)-\alpha+\alpha^{2}\right)\right)}{\left(q\left(1-k_{U}\right)(1-q)-h^{2}(1-\alpha)+\alpha+h\left(2 \alpha-1+k_{U}(1-q)\right)\left(k_{U} q-2(1+\alpha+h \alpha)\right)\right)} .
\end{aligned}
$$

The supplier's optimal profit is given by

$\Pi_{d}^{U}(S)=$

$\frac{\left(1-k_{N}\right)\left(1+q\left(1-k_{U}\right)+(1+h) \alpha\right)\left(2 h^{2}(1-\alpha)-2 \alpha+q\left(k_{U}(1-q)+\alpha+q-1\right)+h\left(2-4 \alpha+q\left(-2+k_{U}+\alpha\right)\right)\right)^{2}}{\left(q\left(1-k_{U}\right)(1-q)-h^{2}(1-\alpha)+\alpha+h\left(2 \alpha-1+k_{U}(1-q)\right)\left(k_{U} q-2(1+\alpha+h \alpha)\right)\right)}$.

(ii) With some algebraic simplification, it can be shown that the corresponding signs of the first-order derivatives are as follows.

$$
\begin{aligned}
\frac{d P_{d n}^{U^{*}}}{d k_{U}} & =\frac{q\left(-2-2 h^{2}-h(4-q(2+\alpha))+q(3-q+\alpha)\right)}{\left(2(1+\alpha+h \alpha)-k_{U} q\right)^{2}} \\
& =\frac{q\left(-2+(q-h)(1-q)-2 h^{2}-h(1-q)\right)}{\left(2(1+\alpha+h \alpha)-k_{U} q\right)^{2}} .
\end{aligned}
$$

This is negative, because $h<q<1$.

$$
\frac{d P_{d n}^{U^{*}}}{d \alpha}=\frac{(1+h)\left(4(1+h)(1+h-q)+\left(2-k_{U}\right) q^{2}\right)}{\left(2+2 \alpha+(1+h)-k_{U} q\right)^{2}} .
$$

This is positive, because $(1+h-q)>0$.

(iii) The derivative of $P^{U^{*}}{ }_{d s}$ with respect to $P^{U^{*}}$ in is derived using the implicit function theorem as follows. Let the left-hand side of Equation (A6) be denoted as $F$. Then, we have 


$$
\frac{d P_{d s}^{U_{1}}}{d P_{d n}^{U_{1}}}=\frac{\frac{d F}{d P_{d n}^{U_{1}}}}{\frac{d F}{d P_{d s}^{U_{1}}}}=\frac{q\left((1+h) \alpha-h+(1+h-q) P_{d n}^{U_{2}}\right)}{\left(1-k_{U}\right)(1-q) q-h^{2}(1-\alpha)+\alpha-h\left(1+k_{U} q-q-2 \alpha\right)}
$$

With some algebraic simplification, it can be shown that the denominator becomes equal to $\left(1-k_{U}\right)(1-q) q+h q\left(1-k_{U}\right)+(1+h)(\alpha+\alpha h-h)$, which is positive. Thus, the sign of the above derivative is positive.

\section{Proof of Proposition 5 (Optimal New Good Price Comparison)}

The optimal new good price under a duopolistic used good structure is given by Equation (7). The new good price under the monopolistic used good regime is given by Equation (2). Taking the difference between the two and solving for the roots of this Equation, which makes it strictly positive, gives us the critical value of $\alpha$ :

$$
\begin{aligned}
& \alpha_{n}= \\
& \frac{\left(4 h^{3}+\left(1-k_{U}\right)(1-q) q\left(2-\left(2-k_{U}\right) q\right)+h^{2}\left(4-2 k_{U} q\right)+h\left(2+\left(8-k_{U}(7-q)-2 q\right) q\right)\right)}{2(1+h)\left(h+2 h^{2}-2 h q+q\left(1-k_{U}\right)\right)} .
\end{aligned}
$$

Now, we know from Proposition 6 that $\left(d P^{U^{*}}{ }_{d n}\right) / d \alpha>0$. Further, with some algebraic simplification, it can be shown that the numerator of this expression is positive. Since the denominator is also positive, this implies that $\alpha_{n}$ is positive. 